Effect of porcine pl acental extract on col I agen product i on i n human ski $n$ fi brobl ast $s$ in vitro

\begin{tabular}{|l|l|}
\hline 著者 & 吉川 智香子 \\
\hline 著者別表示 & Yoshi kawa Chi kako \\
\hline $\begin{array}{l}\text { j our nal or } \\
\text { publ i cat i on t i t l e }\end{array}$ & 博士論文本文Ful I \\
\hline 学位授与番号 & 13301甲第3988号 \\
\hline 学位名 & 博士 (医学) \\
\hline 学位授与年月日 & 2014 03 22 \\
\hline URL & ht t p: //hdl . handl e. net /2297/40561 \\
\hline
\end{tabular}




\title{
Effect of Porcine Placental Extract on Collagen Production in Human Skin Fibroblasts In Vitro
}

Chikako Yoshikawa', Fumihide Takano ${ }^{2,3}$, Yasuhito Ishigaki ${ }^{4}$, Masahiko Okada1, Satoru KYO', Nobutaka Suzuki ${ }^{5}$, Kouichi Sugiura ${ }^{6}$ and $\mathrm{Koji}^{1}$ Koike $^{5,7 *}$

${ }^{1}$ Department of Obstetrics and Gynecology, Graduate School of Medical Science, Kanazawa University, 13-1 Takaramachi, Kanazawa, Ishikawa 920-8641, Japan ${ }^{2}$ Department of Kampo Medicines, Nihon Pharmaceutical University, Ina-machi Komuro, Kita-Adachi-gun, Saitama 362-0806, Japan

${ }^{3}$ Department of Pharmacognosy and Natural Product Chemistry, School of Pharmacy and Pharmaceutical Sciences, Kanazawa University, Kakuma-machi, Kanazawa, Ishikawa 920-1192, Japan

${ }^{4}$ Medical Research Institute, Kanazawa Medical University, 1-1 Daigaku, Uchinada-machi, Kahoku-gun 920-0293, Japan

${ }^{5}$ Department of Complementary and Alternative Medicine, Kanazawa University Graduate School of Medical Science, Kanazawa, Ishikawa 920-8640, Japan

${ }^{6}$ Sugiura Clinic, Hikarigaoka, Kanazawa, Ishikawa921-8142, Japan

${ }^{7}$ Koike Ladies Clinic, Nanbanaka, Osaka Naniwa-ku, Osaka 556-0011, Japan

\begin{abstract}
Placental Extract (PE) has been used as a folk remedy in Asian countries. Human PE is clinically used for the treatment of skin wrinkles because it promotes skin regeneration. In this study, we found that Porcine PE (PPE) promoted collagen production in Normal Human Dermal Fibroblasts (NHDFs). Treatment of NHDFs with PPE at concentrations of $12.5-100 \mu \mathrm{g} / \mathrm{mL}$ enhanced their proliferation and secretion of procollagen $C$ peptide. We also found that expression of intracellular Matrix Metalloproteinase-9 (MMP-9) in PPE-treated NHDFs was decreased in a dose-dependent manner. These results indicate that PPE might affect facial wrinkling partly by enhancing fibroblast proliferation and collagen secretion while inhibiting MMP-9 expression in NHDFs.
\end{abstract}

Keywords: Porcine placental extract; Collagen; Fibroblasts; MMP-9

\section{Introduction}

The placenta is a temporary organ present during gestation, which supplies oxygen and nutrients to the developing fetus [1]. It is expelled from the body after birth and the nutritional substances can be extracted to prepare a Placental Extract (PE). Such PEs reportedly contained enzymes such as alkaline acid phosphatase and glutamic oxalo acetic transaminase, as well as nucleic acids, vitamins, amino acids, steroids, fatty acids, and minerals [2]. PEs are a traditional medicine used for wound healing, because of immune tropic and anti-inflammatory activities, and as a cosmetic supplement in many Asian countries [3]. In Asia, subcutaneous or intramuscular injection of Human PE (HPE), a hydrolysate of the human placenta commercially named Laennec (Japan Bio Products, Tokyo, Japan), has been recently used for the treatment of various disorders including climacteric symptoms, non-healing wounds and chronic varicose ulcers [4-7]. Furthermore, HPE is clinically and cosmetically used for the treatment of skin wrinkles because of its promotion of skin regeneration [8,9]. HPE is also a component of various skin ointments because it promotes skin revitalizing and melanocyte growth, and exhibits pigment-inducing activities as well as for the treatment of skin hypersensitivity-like dermatitis and psoriasis [10].

Recently, Porcine PE (PPE) has been developed as an orally administered supplement for the same purposes as those of HPE. In a previous study, PPE was found to promote wound healing in rats with thermal injury [11]. PPE treatment also inhibits the activation of antigen-presenting cells including macrophages, which leads to down-regulation of pro inflammatory cytokines, suggesting a potential therapeutic application of PPE in the modulation of skin inflammation [12]. Our previous studies demonstrate that oral administration of PPE to human subjects is significantly effective for the reduction of knee pain in post-menopausal women and improvement of climacteric symptoms in pre and post-menopausal women $[13,14]$.

Wrinkles are caused by aging, genetics, and environmental factors such as ultraviolet radiation, as well as smoking and estrogen deficiency [15-19]. Among these factors, the severity of wrinkles correlates strongly with age. As human skin ages, it becomes thin and shows a decrease in elasticity, glycosamino glycans, and collagen [18,20-23].

Collagen is the predominant fibrous protein of the extracellular matrix and is a major constituent of connective tissue in the human body. About 3-6\% of total tissue protein in the body is collagen, and the functional properties of skin depend on the integrity of collagen in the dermis. Changes in collagen expression occur during wound healing, new bone development, and aging [24]. Therefore, the control of collagen metabolism might be useful for a variety of therapeutic and cosmetic applications.

We have found that oral administration of PPE to pre and postmenopausal women leads to a reduction in the width of wrinkles below the eye. However, the mechanism regulating collagen production in human fibroblasts by PPE has not been elucidated in detail. In this study, we found that PPE stimulated collagen production and inhibited secretion of a collagen-degrading enzyme, Metalloproteinase (MMP)9, in Normal Human Dermal Fibroblasts (NHDFs).

\section{Materials and Methods}

\section{PPE}

The PPE (JBP porcine 100, Tokyo, Japan) used in this study was provided from Japan Bio Products. The porcine placenta was collected in Japan and treated with a protease and heat sterilization prior to freeze drying, grinding, and transfer into capsules. The contents of

*Corresponding author: Koji Koike, Department of Complementary and Alternative Medicine, Kanazawa University Graduate School of Medical Science, Kanazawa, Ishikawa 920-8640, Japan, Tel: +81-76-265-2121; Fax: +81-76-234-4266; E-mail: k-koike@med.kanazawa-u.ac.jp

Received October 23, 2013; Accepted November 24, 2013; Published November 30, 2013

Citation: Yoshikawa C, Takano F, Ishigaki Y, Okada M, KYO S, et al. (2013) Effect of Porcine Placental Extract on Collagen Production in Human Skin Fibroblasts In Vitro. Gynecol Obstet 3: 186 doi:10.4172/2161-0932.1000186

Copyright: (c) 2013 Yoshikawa C, et al. This is an open-access article distributed under the terms of the Creative Commons Attribution License, which permits unrestricted use, distribution, and reproduction in any medium, provided the original author and source are credited. 
these capsules were dissolved in distilled water for use in experiments.

\section{Cell culture}

NHDFs were obtained from neonatal foreskin and purchased form Takara Bio (Shiga, Japan). The cells were cultured in Dulbecco's Modified Eagle's Medium (DMEM; Sigma-Aldrich, St. Louis, USA) supplemented with $10 \%$ Fetal Bovine Serum (FBS) at $37^{\circ} \mathrm{C}$ with $5 \%$ $\mathrm{CO}_{2}$. NHDFs were used for all experiments after 3 passages.

\section{Cell proliferation assay}

Cell proliferation was assessed by a MTT assay [25]. NHDFs $\left(1 \times 10^{4}\right.$ cells $/ \mathrm{mL}$ ) were cultured in 96-well plates with DMEM containing $10 \%$ FBS for $2 \mathrm{~h}$. PPE was added to the medium at various concentrations, and then the cells were incubated for $48 \mathrm{~h}$. The medium was aspirated and replaced with $100 \mu \mathrm{L}$ of fresh medium and $20 \mu \mathrm{L}$ of a MTT solution $\left(0.5 \%(\mathrm{w} / \mathrm{v})\right.$ in $\mathrm{Ca}^{2+} / \mathrm{Mg}^{2+}$-free Phosphate-Buffered Saline [PBS]; Nacarai Tesque, Kyoto, Japan) per well followed by $4 \mathrm{~h}$ of incubation. Then, 150 $\mu \mathrm{L}$ of a SDS solution per well was added, followed by incubation for $18 \mathrm{~h}$. The plates were then shaken for $15 \mathrm{~min}$ and read at a $570-\mathrm{nm}$ wavelength to obtain the absorbance values.

\section{Measurement of procollagen type I C-Peptide (PIP) by an Enzyme Immune Assay (EIA)}

PIP was used as a marker for procollagen secretion. NHDFs $\left(1 \times 10^{4}\right.$ cells $/ \mathrm{mL}$ ) were cultured in 24-well plates with DMEM containing $10 \%$ FBS. At $80 \%$ confluence, the medium was replaced with DMEM containing $0.5 \% \mathrm{FBS}$, and the cells were cultured overnight. Then, the cells were stimulated with various concentrations of PPE. Culture supernatants were harvested after $24-72 \mathrm{~h}$ and frozen at $-80^{\circ} \mathrm{C}$ until use. The level of PIP in the supernatants was measured by a commercially available EIA kit (Takara Bio, Shiga, Japan) according to the manufacturer's instructions.

\section{Western blot analysis}

NHDFs were cultured in 60-mm dishes with DMEM containing $10 \%$ FBS. The method for culturing the cells was similar to that described for determination of PIP levels.

In brief, after $72 \mathrm{~h}$ of culture, the cells were lysed with a modified radio immune precipitation assay buffer containing protease and phosphatase inhibitors $(1 \mu \mathrm{g} / \mathrm{mL}$ aprotinin, $1 \mu \mathrm{g} / \mathrm{mL}$ leupeptin, $1 \mu \mathrm{g} /$ $\mathrm{mL}$ pepstatinA, $100 \mathrm{mM}$ PMSF, $200 \mathrm{mM} \mathrm{NaVO}, 100 \mathrm{mMNaF}$, and $2 \times$ complete Mini; (Roche applied science, Mannheim, Germany)). Lysates were centrifuged to remove cellular debris, and the super natants were collected as the protein extract. Protein concentrations were measured using a BCA protein assay kit (Thermo Fisher Scientific, USA). Each protein sample $(10 \mu \mathrm{g})$ was size fractionated by SDSpolyacrylamide gel electrophoresis using $12 \%$ mini protean TGX gels (Bio-Rad Laboratories, CA, USA). Separated proteins were transferred to poly vinylidene fluoride membranes (GE Healthcare, England, UK). The membranes were then blocked for $1 \mathrm{~h}$ at room temperature with 5\% skim milk powder in PBS containing 0.05\% Tween 20 (PBS-T) and then incubated with primary antibodies diluted in PBS-T at $4^{\circ} \mathrm{C}$. The primary antibodies were rabbit anti MMP-9 (1:1000) and mouse anti $\beta$-actin (1:5000) (Santa Cruz Biotechnology, TX, USA).

The membranes were washed several times with PBS-T and then incubated with secondary antibodies diluted in PBS-T for $1 \mathrm{~h}$ at room temperature. Secondary antibodies were goat anti-rabbit IgGHorseradish Peroxidase (HRP) (1:2000) and donkey anti-mouse IgG-HRP (1:5000) purchased from Santa Cruz Biotechnology. The membranes were washed several times with PBS-T and Milli-Q water.
Reactive proteins were visualized with ECL detection reagents and autoradiography using high-performance auto radiographic film (GE Healthcare UK Ltd, Buckinghamshire, England).

\section{Statistical analysis}

Results are expressed as the mean \pm Standard Deviation (SD). Differences between groups were assessed with the Wilcox on signedrank test. The Mann-Whitney nonparametric $U$ test was used to evaluate differences between two groups. $\mathrm{P}<0.05$ was considered to be statistically significant.

\section{Results}

\section{PPE induces NHDF proliferation}

It is well known that skin fibroblasts express extracellular matrix proteins including collagen, and play a critical role in skin regeneration [26]. We first investigated the effect of PPE on the proliferation of cultured NHDFs. As indicated in Figure 1, NHDFs treated with $100 \mu \mathrm{g} /$ $\mathrm{mL}$ PPE showed a higher proliferation rate than control. The ability of PPE to increase cell proliferation was dose dependent at concentrations in the range of $6.25-100 \mu \mathrm{g} / \mathrm{mL}$ (Figure 1A). During 24-72 h of culture, $50 \mu \mathrm{g} / \mathrm{mL}$ PPE enhanced cell proliferation compared with that in the control (Figure 1B).

\section{Effect of PPE on PIP production}

To investigate the effect of PPE on collagen synthesis and/or secretion in NHDFs, we measured the amount of PIP in the culture supernatants of NHDFs after stimulation with PPE. As illustrated in Figure 2, cells treated with PPE produced PIP in a dose-dependent manner. The PIP levels in the culture supernatants accumulated significantly within $72 \mathrm{~h}$ following addition of $50 \mu \mathrm{g} / \mathrm{mL}$ PPE, where as the PIP levels were decreased by $200 \mu \mathrm{g} / \mathrm{mL}$ PPE (Figures $2 \mathrm{~A}$ and $2 \mathrm{~B}$ ).

\section{Effect of PPE on intracellular expression of MMP-9 in NHDFs}

MMP-9 is a member of the matrix metalloproteinase family that normally remodels the extracellular matrix, and has been shown to play an important role in collagen degradation [27]. We therefore investigated the effect of PPE on MMP-9 expression in NHDFs. After $72 \mathrm{~h}$ of cultivation, western blot analysis revealed that PPE at concentrations in the range of $12.5-50 \mu \mathrm{g} / \mathrm{mL}$ significantly decreased MMP-9 expression in a dose-dependent manner (Figure 3).
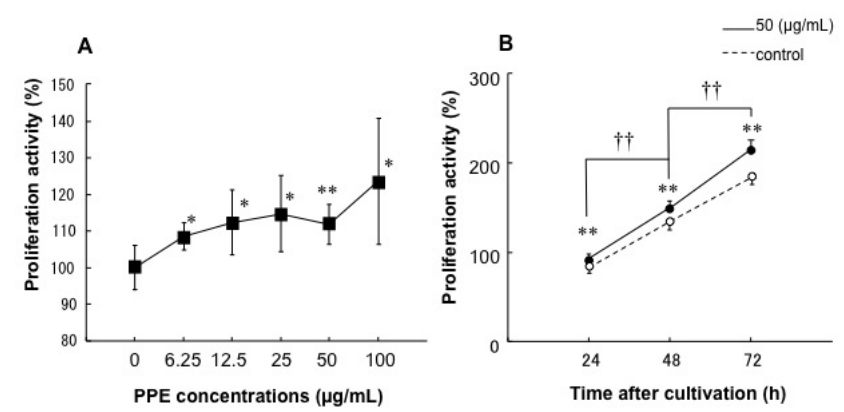

Figure 1: Effects of PPE on the proliferation of cultured NHDFs. Cells were treated with or without PPE at various concentrations. Cell proliferation was measured by an MTT assay. A Proliferation of NHD Fstreated with PPE at various concentrations. B.Timecourse of NHDF proliferation. Data are indicated as the mean \pm SD of six independent experiments. ${ }^{*} p<0.05$ and ${ }^{* *} p<0.01$ vs. control culture, ${ }^{+\dagger} p<0.01$ vs. control culture at 24 and $48 \mathrm{~h}$. 

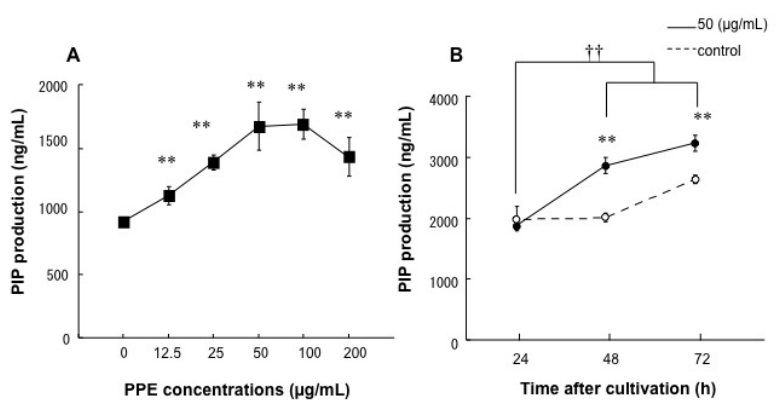

Figure 2: Effects of PPE on PIP production in cultured NHDFs. Cells were treated with or without PPE at various concentrations. Culture supernatants were collected to measure the levels of PIP by EIA. Data are indicated as the mean \pm SD of four independent experiments. ${ }^{*} p<0.05$ and ${ }^{* *} p<0.01$ vs. control culture, ${ }^{+\dagger} p<0.01 \mathrm{vs}$. control culture at 24 and $48 \mathrm{~h}$

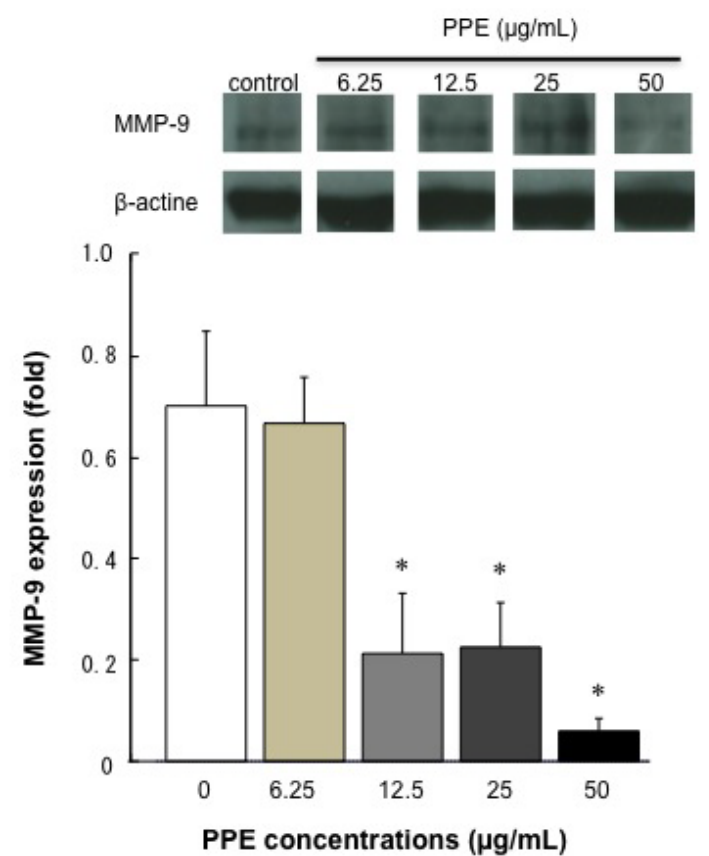

Figure 3: Effects of PPE on PIP production in cultured NHDFs. Cells were treated with or without the indicated concentrations of PPE for $72 \mathrm{~h}$. Intracellular MMP-9 protein was then measured by western blot analysis. The protein expression levels of MMP-9 were normalized to $\beta$-actin levels. Data are indicated as the mean \pm SD of three independent experiments. ${ }^{* *} p<0.01$ vs. control culture.

\section{Discussion}

HPE is used as a cosmetic supplement for skin care and skin pigmentation [9]. It has also been reported to play a role in skin regeneration [8,9]. However, PPE applications have not included improving the appearance of wrinkles. It is known that collagen precursor (procollagen) molecules are synthesized in fibroblasts [26]. In this study, we found that the proliferation of fibroblasts was enhanced by PPE. A recent study has shown that PPE induces skin fibroblasts into $S$ phase and increases the protein level of basic fibroblast growth factor, which is consistent with our results [11].

We also found that PPE significantly increased collagen production in NHDFs at $72 \mathrm{~h}$ of culture, suggesting that PPE has a stimulatory effect on collagen production. Skin collagen has a central role in dermal mechanical strength as a component of the extracellular matrix. Constitutive assemblies are principally initiated by growth factors and hormones such as estrogen [28]. The decline of dermal collagen content after menopause is a major factor in the appearance of wrinkling [18]. Furthermore, there is a strong correlation between skin collagen loss and estrogen deficiency during climacteric, which also suggests that estrogen deficiency may be involved in the decrease of skin collagen, leading to skin wrinkling in post-menopausal women $[18,19]$. Our recent study demonstrated that women treated with hormone replacement therapy show a significant decrease of the width of wrinkles compared with that of untreated women [29]. PPE had no effects on bone mineral density or the weight of the uterus in ovary ectomized female mice and 24 weeks treatment with PPE did not change the levels of serum estrogen or thyroid hormones in postmenopausal women [14]. This suggests that estrogen and thyroid hormones are not involved in PPE-mediated bioactive effects. Indeed, progesterone and oestradiol have little effect on cell proliferation [11]. Therefore, it is likely that the induction of cell proliferation and collagen production by PPE was not caused by these hormones.

The amount of collagen in the dermis is the net result of its synthesis and degradation. MMPs are a family of structurally related enzymes, including collagenase-1 (MMP-1), collagenase-3 (MMP-13), gelatinase A and B (MMP-2 and MMP-9), stromelysin (MMP-3), and membranetype MMPs, which are capable of degrading all components of the extracellular matrix such as collagen, elastin, fibronectin, proteoglycans, and laminin [27]. In particular, MMP-1 degrades type I and III fibrillar collagen, MMP-9 further degrades the collagen fragments, and MMP-3 degrades type IV collagen and activates pro-MMP-1 [30,31].

In this study, PPE reduced the protein levels of MMP-9 in NHDFs. Therefore, these results suggest that PPE prevents degradation of collagen by decreasing MMP-9 protein expression. To investigate the relation between mRNA and protein expression of MMP-9, real-time reverse transcription-polymerase chain reaction was also performed. The low level of MMP-9 mRNA was detectable, while the expression value of MMP-9 varied widely in the RT-PCR method. We observed the results, which PPE has a tendency to suppress the mRNA expression (data not shown).

A limitation of this study is that we have not identified the active constituents in PPE that affect collagen production. Further investigation is needed to determine the active constituents in PPE. However, such substances in PPE are likely to be small molecules including tripeptides and dipeptides, because PPE has shown bioactivity via oral administration for the treatment of wrinkles, climacteric symptoms, and knee pain $[13,14]$. Collagen is characterized by a triple helical structure with a repeating sequence of Glycine $(\mathrm{G})-\mathrm{X}-\mathrm{Y}$, where amino acids $\mathrm{X}$ and $\mathrm{Y}$ are high-frequency proline and hydroxyl proline, respectively [32]. Togashi et al., reported that HPE contains G-X-Y tripeptides [32]. The G-X-Y tripeptide reportedly increases collagen and hyaluronic acid contents in cultured fibroblasts [33]. We recently found that PPE contains proline and hydroxyl proline by amino acid analysis. We are currently analyzing the active constituents, particularly the peptides, in PPE.

In the present study, we found that PPE stimulates the proliferation of NHDFs as well as the production of collagen, and inhibits MMP9 production. The fibroblast reportedly produces collagen and bind to collagen fibril through integrin, which modulates skin thickness $[34,35]$. It is also reported that cell proliferation is regulated by surrounding circumstance, especially related to density, and density of dermis is linked to collagen production of fibroblast [36,37]. Thus, 
we discussed that PPE have beneficial effect to wound healing or facial wrinkling since proliferation cell may compensate the tissue spatially and cells secrete collagen in sufficiently dense circumstance. Taken together PPE may be useful supplement for the treatment of cosmetic facial wrinkling same as HPE.

\section{Acknowledgments}

We thank Mr Taiichi Kaku (Japan Bio Products) for providing the PPE (JBP porcine 100).

\section{Source of Funding}

This work was partially supported by the NPO Science Research Center for Alternative Medicine, Kanazawa, Ishikawa, Japan.

\section{References}

1. Lewis RM, Cleal JK, Hanson MA (2012) Review: Placenta, evolution and lifelong health. Placenta 33 Suppl: S28-S32.

2. Ansari KU, Gupta N, Bapat SK (1994) An experimental and clinical evaluation of immunomodulating potential of human placental extract. Indian J Pharmacol 26: $130-132$

3. Tonello G, Daglio M, Zaccarelli N, Sottofattori E, Mazzei M, et al. (1996) Characterization and quantitation of the active polynucleotide fraction (PDRN) from human placenta, a tissue repair stimulating agent. J Pharm Biomed Anal 14: $1555-1560$

4. Kong MH, Lee EJ, Lee SY, Cho SJ, Hong YS, et al. (2008) Effect of human placental extract on menopausal symptoms, fatigue, and risk factors for cardiovascular disease in middle-aged Korean women. Menopause 15: 296 303

5. Shukla VK, Rasheed MA, Kumar M, Gupta SK, Pandey SS (2004) A trial to determine the role of placental extract in the treatment of chronic non-healing wounds. J Wound Care 13: 177-179.

6. Tiwary SK, Shukla D, Tripathi AK, Agrawal S, Singh MK, et al. (2006) Effect of placental-extract gel and cream on non-healing wounds. J Wound Care 15: 325-328.

7. Burgos H, Herd A, Bennett JP (1989) Placental angiogenic and growth factors in the treatment of chronic varicose ulcers: preliminary communication. J R Soc Med 82: 598-599.

8. Saurat JH, Didierjean L, Mérot Y, Salomon D (1988) Blistering skin disease in a man after injections of human placental extracts. BMJ 297: 775

9. Pal P, Roy R, Datta PK, Dutta AK, Biswas B, et al. (1995) Hydroalcoholic human placental extract: skin pigmenting activity and gross chemical composition. Int J Dermatol 34: 61-66.

10. Pal P, Mallick S, Mandal SK, Das M, Dutta AK, et al. (2002) A human placental extract: in vivo and in vitro assessments of its melanocyte growth and pigmentinducing activities. Int J Dermatol 41: 760-767.

11. Wu CH, Chang GY, Chang WC, Hsu CT, Chen RS (2003) Wound healing effects of porcine placental extracts on rats with thermal injury. $\mathrm{Br} \mathrm{J}$ Dermatol 148: 236-245.

12. Jash A, Kwon HK, Sahoo A, Lee CG, So JS, et al. (2011) Topical application of porcine placenta extract inhibits the progression of experimental contact hypersensitivity. J Ethnopharmacol 133: 654-662.

13. Koike K, Yamamoto Y, Suzuki N, Yamazaki R, Yoshikawa C, et al. (2012) Efficacy of porcine placental extracts with hormone therapy for postmenopausal women with knee pain. Climacteric 15: 30-35.

14. Koike K, Yamamoto Y, Suzuki N, Yamazaki R, Yoshikawa C, et al. (2013) Efficacy of porcine placental extract on climacteric symptoms in peri- and postmenopausal women. Climacteric 16: 28-35.

15. Yin L, Morita A, Tsuji T (2001) Skin aging induced by ultraviolet exposure and tobacco smoking: evidence from epidemiological and molecular studies. Photodermatol Photoimmunol Photomed 17: 178-183.

16. Chung JH (2003) Photoaging in Asians. Photodermatol Photoimmuno Photomed 19: 109-121.

17. Castelo-Branco C, Figueras F, Martínez de Osaba MJ, Vanrell JA (1998) Facial wrinkling in postmenopausal women. Effects of smoking status and hormone replacement therapy. Maturitas 29: 75-86.
18. Calleja-Agius J, Muscat-Baron Y, Brincat MP (2007) Skin ageing. Menopause Int 13: 60-64.

19. Youn CS, Kwon OS, Won CH, Hwang EJ, Park BJ, et al. (2003) Effect of pregnancy and menopause on facial wrinkling in women. Acta Derm Venereol 83: $419-424$

20. Boyer G, Laquièze L, Le Bot A, Laquièze S, Zahouani H (2009) Dynamic indentation on human skin in vivo: ageing effects. Skin Res Technol 15: 55-67.

21. Contet-Audonneau JL, Jeanmaire C, Pauly G (1999) A histological study of human wrinkle structures: comparison between sun-exposed areas of the face with or without wrinkles, and sun-protected areas. Br J Dermatol 140: 10381047.

22. Fleischmajer R, Perlish JS, Bashey RI (1972) Human derma glycosaminoglycans and aging. Biochim Biophys Acta 279: 265-275.

23. Brincat M, Moniz CJ, Studd JW, Darby A, Magos A, et al. (1985) Long-term effects of the menopause and sex hormones on skin thickness. $\mathrm{Br} J$ Obstet Gynaecol 92: 256-259.

24. Cardinale GJ, Udenfriend S (1974) Prolyl hydroxylase. Adv Enzymol Relat Areas Mol Biol 41: 245-300.

25. Mosmann T (1983) Rapid colorimetric assay for cellular growth and survival: application to proliferation and cytotoxicity assays. J Immunol Methods 65: 55 63.

26. Pinnell SR (1982) Regulation of collagen synthesis. J InvestDermatol 79: 7376.

27. Inomata S, Matsunaga Y, Amano S, Takada K, Kobayashi K, et al. (2003) Possible involvement of gelatinases in basement membrane damage and wrinkle formation in chronically ultraviolet B-exposed hairless mouse. J Invest Dermatol 120: 128-134.

28. Hall G, Phillips TJ (2005) Estrogen and skin: the effects of estrogen, menopause and hormone replacement therapy on the skin. J Am Acad Dermatol 53: 555 568.

29. Yoshikawa C, Koike K, Yamazaki R, Akazawa-Kudoh S, Takano F, et al. (2011) Evaluation of skin condition by skin analyzer in adult women: Establishment of normal ranges for values of parameters of skin condition and effect of hormone replacement therapy on skin condition. JMWH 19: 207-215

30. Fisher GJ, Datta SC, Talwar HS, Wang ZQ, Varani J, et al. (1996) Molecular basis of sun-induced premature skin ageing and retinoid antagonism. Nature 379: 335-339.

31. Fisher GJ, Talwar HS, Lin J, Lin P, McPhillips F, et al. (1998) Retinoic acid inhibits induction of c-Jun protein by ultraviolet radiation that occurs subsequent to activation of mitogen-activated protein kinase pathways in human skin in vivo. J Clin Invest 101: 1432-1440.

32. Togashi S, Takahashi N, Iwama M, Watanabe S, Tamagawa K, et al. (2002) Antioxidative collagen-derived peptides in human-placenta extract. Placenta 23: 497-502

33. Kikuta T, Sakai Y, Tuda Y (2003) The development of highly functional collagen tripeptide. Fragr J 31: 61-67.

34. Fujimura T, Moriwaki S, Imokawa G, Takema Y (2007) Crucial role of fibroblas integrins alpha2 and beta1 in maintaining the structural and mechanical properties of the skin. J Dermatol Sci 45: 45-53.

35. Hynes RO (1992) Integrins: versatility, modulation, and signaling in cell adhesion. Cell 69: 11-25.

36. Nishiyama T, Tsunenaga M, Nakayama Y, Adachi E, Hayashi T (1989) Growth rate of human fibroblasts is repressed by the culture within reconstituted collagen matrix but not by the culture on the matrix. Matrix 9: 193-199.

37. Freiberger H, Grove D, Sivarajah A, Pinnell SR (1980) Procollagen I synthesis in human skin fibroblasts: effect on culture conditions on biosynthesis. J Invest Dermatol 75: 425-430.

Citation: Yoshikawa C, Takano F, Ishigaki Y, Okada M, KYO S, et al. (2013) Effect of Porcine Placental Extract on Collagen Production in Human Skin Fibroblasts In Vitro. Gynecol Obstet 3: 186 doi:10.4172/2161-0932.1000186 